\title{
EL LODO ALFANO: COMENTARIO A LA SENTENCIA 262/2009 DE LA CORTE COSTITUZIONALE ITALIANA
}

\author{
DAVID DELGADO RAMOS
}


SUMARIO

1. INTRODUCCIÓN. 2. ANTECEDENTES: EL LODO MACCANICOSCHIFANI. 3. EL LODO ALFANO. 4. DERECHO COMPARADO. 5. CONCLUSIÓN. 6. BIBLIOGRAFÍA. 


\title{
EL LODO ALFANO: COMENTARIO A LA SENTENCIA 262/2009 DE LA CORTE COSTITUZIONALE ITALIANA
}

POR

\author{
DAVID DELGADO RAMOS
}

Universidad Complutense de Madrid

\section{INTRODUCCIÓN}

El pasado 7 de octubre de 2009 la Corte Costituzionale Italiana falló la sentencia sobre la Legge 23 luglio 2008, n. 124, llamada Lodo Alfano. La sentencia declaró, por una amplia mayoría de nueve votos frente a seis, la inconstitucionalidad (l'illegittimità costituzionale) del artículo 1 de la ley por violación de los artículos $3^{1}$ y $138^{2}$ de la Constitución, incluyendo además en la motivación de su fallo la

${ }^{1}$ Artículo 3: «Tutti i cittadini hanno pari dignità sociale e sono eguali davanti alla legge, senza distinzione di sesso, di razza, di lingua, di religione, di opinioni politiche, di condizioni personali e sociali.

E compito della Repubblica rimuovere gli ostacoli di ordine economico e sociale, che, limitando di fatto la libertà e l'eguaglianza dei cittadini, impediscono il pieno sviluppo della persona umana e l'effettiva partecipazione di tutti i lavoratori all'organizzazione politica, economica e sociale del Paesen.

2 Artículo 138: "Le leggi di revisione della Costituzione e le altre leggi costituzionali sono adottate da ciascuna Camera con due successive deliberazioni ad intervallo non minore di tre mesi, e sono approvate a maggioranza assoluta dei componenti di ciascuna Camera nella seconda votazione.

Le leggi stesse sono sottoposte a referendum popolare quando, entro tre mesi dalla loro pubblicazione, ne facciano domanda un quinto dei membri di una Camera o cinquecentomila elettori o cinque Consigli regionali.

La legge sottoposta a referendum non è promulgata, se non è approvata dalla maggioranza dei voti validi.

Non si fa luogo a referendum se la legge è stata approvata nella seconda votazione da ciascuna delle Camere a maggioranza di due terzi dei suoi componentii. 
necesidad de una ley constitucional no una simple ley ordinaria, para introducir la inmunidad prevista en la ley para las cuatro magistraturas del Estado ${ }^{3}$.

La sentencia sustancia en su fallo la constitucionalidad de la Ley tras las cuestiones de constitucionalidad que con fecha 26 de septiembre y 4 de octubre de 2008 fueron presentadas por el Tribunal de Milán, que enjuiciaba al presidente del Consejo de Ministros Silvio Berlusconi, por los casos David Mills ${ }^{4}$ y Mediaset $^{5}$, entre otros, y que fueron objeto de consulta sobre su constitucionalidad tras la duda que en tales procesos sostuvo el fiscal de Milán Fabio de Pasquale. El Tribunal que enjuiciaba ambos procesos, ante la promulgación y entrada en vigor de la Ley, que suspendía los procesos que se sustanciaban ante el Tribunal, estimó el fundamento jurídico que sostenía la duda del fiscal y presentó ante la Corte Costituzionale las cuestiones de constitucionalidad. Asimismo, el GIP ${ }^{6} \mathrm{de}$ Roma, con fecha 26 de septiembre de 2008 también presentó una tercera consulta a la Corte por otro proceso contra el premier por instigación a la corrupción respecto de algunos senadores elegidos en el extranjero durante la pasada legislatura.

Mediante este trabajo se expondrá la génesis de la Ley en su contexto jurídico-político y su antecedente jurídico, el Lodo Maccanico-Schifani, también declarado inconstitucional. Posteriormente, se analizará la sentencia de la Corte Costituzionale y se situará jurídicamente al Lodo en el contexto constitucional europeo, analizando las analogías y diferencias con otros ordenamientos.

\section{ANTECEDENTES: EL LODO MACCANICO-SCHIFANI}

El precedente del llamado Lodo Alfano es la Ley de 20 de junio de 2003, número 140, llamada Lodo Maccanico-Schifani ${ }^{7}$, declarada parcialmente in-

${ }^{3}$ Presidente de la República, Presidente del Senado, Presidente de la Congreso de los Diputados y Presidente del Consejo de Ministros.

${ }^{4}$ El caso Mills hace referencia al soborno de 600.000 dólares que recibió, —según recoge la sentencia - el abogado británico David Mills, —esposo de una ministra del Gobierno de Tony Blair- por parte de Silvio Berlusconi, por declarar falsamente dos veces en dos procesos que le afectaban: soborno a la Guardia di Finanza (que investigaba la posible evasión fiscal por parte de algunas de sus sociedades) y caso All Iberian (financiación ilegal del Partido Socialista Italiano de Bettino Craxi).

5 El caso Mediaset, en cambio, refiere a la compraventa de derechos televisivos por vía indirecta a través de sociedades extranjeras controladas por Berlusconi, que revendían, a su vez, los mismos derechos a otras sociedades gemelas, elevando el precio en cada paso. La diferencia entre el valor real y el final permitía obtener dinero negro.

${ }^{6}$ Giudice per le indagini preliminari. Su equivalente español es el Juzgado de Instrucción. 
constitucional por la Corte Costituzionale el 20 de enero de 2004. El objetivo de esta ley, presentada por el senador de la coalición de centro-izquierda «La Margherita» Antonio Maccanico, era preservar la imagen del Estado italiano durante y sólo durante la Presidencia rotatoria de turno de la Unión Europea, que ostentaría Italia en el segundo semestre de 2003, desde el primero de julio. El senador consideraba que la imagen del Estado se vería gravemente perjudicada internacionalmente por los públicos procesos que en aquel momento tenía el Presidente del Consejo de Ministros, Silvio Berlusconi ${ }^{8}$, cuyo máximo exponente era el proceso $\mathrm{SME}^{9}$. Por tanto, consideró necesaria una ley que suspendiese los procesos penales que las cinco altas magistraturas ${ }^{10}$ del Estado pudiesen tener con independencia de si los eventuales delitos o faltas objeto del proceso penal hubiesen acaecido antes de la asunción del cargo o durante el ejercicio de los mismos.

El originario Lodo del senador Antonio Maccanico fue progresivamente modificado por el senador Schifani, de la coalición de centro-derecha de Berlusconi, de tal suerte y tantas modificaciones que acabó convirtiéndose en el Lodo Maccanico-Schifani-Berlusconi.

Tras su entrada en vigor el 21 de junio de 2003, fue objeto de una cuestión de inconstitucionalidad interpuesta por el Tribunal de Milán con fecha de 30 de junio de 2003, al considerar este Tribunal que «la suspensión automática, generalizada y sin fijación de un término final, viola el artículo 3 de la Constitución, en relación con el artículo 112 de la Constitución, que sanciona la obligatoriedad de la acción penal; en segundo lugar, referido a los artículos 68, 90 y 96 de la Constitución, en tanto se atribuye a las personas que ostentan los altos cargos del Estado antes mencionados una prerrogativa no prevista en las citadas disposiciones constitucionales, que serían modificadas de una forma ilegitima con una ley ordinaria, violando también el artículo 138 de la Constitución».

7 «Disposizioni per l'attuazione dell'articolo 68 della Costituzione nonché in materia di processi penali nei confronti delle alte carche dello Statom.

8 Silvio Berlusconi ha sido tres veces Presidente del Consejo de Ministros (mayo 1994-enero 1995, enero 2001-mayo 2006, y en la actualidad, desde mayo de 2008).

9 Silvio Berlusconi fue acusado de corrupción en la tentativa de compra de esta sociedad agroalimentaria. El proceso, en lo referente a Berlusconi, fue suspendido judicialmente por la promulgación del Lodo Schifani, pero tras la declaración de inconstitucionalidad del mismo, fue reabierto. Berlusconi fue exonerado de responsabilidad criminal de algunos hechos por prescripción de los mismos y absuelto por insustancialidad del delito de corrupción en la fallida compra de esta sociedad, pero el Tribunal de Milán consideró probada la corrupción en otros supuestos.

${ }^{10}$ Las cuatro anteriormente mencionadas más el Presidente de la Corte Costituzionale. 
La Corte Costituzionale declaró la inconstitucionalidad del artículo 1 de la Ley $^{11}$ en su totalidad ${ }^{12}$ por ser contrario a los artículos 3 y $24^{13}$ de la Constitución, que consagran el principio de igualdad ${ }^{14} \mathrm{y}$ la tutela judicial efectiva, respectivamente, pero mantuvo intacta la constitucionalidad del resto del articulado de la Ley. La Corte expone que «Se ha afirmado, para sostener la legitimidad constitucional de la ley, que ningún derecho es definitivamente sacrificado, ningún principio constitucional es abandonado para siempre. La tesis no puede ser estimada. A la efectividad del ejercicio de la jurisdicción no son indiferentes los tiempos del proceso. Anteriormente a que fuese sancionado expresamente por la Constitución el principio de su razonable duración (artículo 111, párrafo segundo), esta Corte había sostenido que un estancamiento del proceso por un tiempo indefinido e indeterminado vulneraría el derecho de acción y defensa (sentencia número 354, 1996) y que la posibilidad de reiteradas suspensiones lesionaría el bien constitucional de la eficiencia del proceso (sentencia 353, 1996)».

La doctrina consideró que el Lodo no era «razonable porque asimila lo inasimilable (juntando en una única disciplina cargos distintos por su investidura y naturaleza de las funciones) y diferencia aquello que no es distinguible (el régimen procesal de los Presidentes de las Cámaras, del Consejo de Ministros y de la Corte Constitucio-

11 Artículo 1: «1. Non possono essere sottoposti a processi penali, per qualsiasi reato anche riguardante fatti antecedente l'assunzione della carica o della funzione, fino alla cessazione delle medesime: il Presidente della Repubblica, salvo quanto previsto dall'articolo 90 della Costituzione, il Presidente del Senato della Repubblica, il Presidente della Camera dei deputati, il Presidente del Consiglio dei Ministri, salvo quanto previsto dall'articolo 96 della Costituzione, il Presidente della Corte Costituzionale.

2. Dalla data di entrata in vigore della presente legge sono sospesi, nei confronti dei soggetti di cui al comma 1 e salvo quanto previsto dagli articoli 90 e 96 della Costituzione, i processi penali in corso in ogni fase, stato o grado, per qualsiasi reato anche riguardante fatti antecedente l'assunzione della carica o della funzione, fino alla cessazione delle medesime.

3. Nelle hipótesis di cui ai commi precedente si applicano le disposizioni dell'articolo 159 del codice penale».

${ }_{12}$ Fue considerado inconstitucional en su totalidad aunque el Tribunal de Milán sólo presentó cuestión de constitucionalidad respecto al párrafo segundo del artículo primero de la Ley por considerar la Corte que tienen la misma sustancial finalidad y el mismo ámbito subjetivo de aplicación y porque entran en contraste con los mismos preceptos constitucionales (artículos 3 y 24 de la Constitución italiana).

13 Artículo 24: "Tutti possono agire in giudizio per la tutela dei propri diritti e interessi legittimi. La difesa è diritto inviolabile in ogni stato e grado del procedimento. Sono assicurati ai non abbienti, con appositi istituti, i mezzi per agire e difendersi davanti ad ogni giurisdizione. La legge determina le condizioni e i modi per la riparazione degli errori giudiziari».

${ }^{14}$ Como expone Vitale respecto a la doctrina constitucional sobre la constitucionalidad de las leyes en Italia, "La Corte Costituzionale utilizza il principio di uguaglianza come parametro per valutare la legitimittà costituzionale delle leggì. VITALE, Agostino. Breve Commentario della nuova Costituzione Italiana. Edizioni Philos, Roma, 2003, p. 27. 
nal, respecto a los componentes de los órganos por ellos presididos ${ }^{15}$ )». Se discutía también por la doctrina el hecho de que la ley fuese ordinaria, no constitucional ${ }^{16}$. La propia Corte, en su sentencia, indirectamente afirmaba — como de nuevo afirmará cuando dicte sentencia sobre la constitucionalidad del Lodo Alfano- que la inconstitucionalidad del Lodo se hubiese resuelto si hubiese sido una ley constitucional, no una simple ley ordinaria, puesto que al crear un régimen ad hoc, ad personam para un determinado colectivo de personas en razón de su cargo, se vulneraba el principio constitucional de la igualdad de todos ante la ley, lo que constituía una modificación constitucional que no podía hacerse por simple ley.

La Corte Costituzionale, el mismo día, resolvió sobre la admisibilidad de un referéndum derogatorio ${ }^{17}$ del artículo 1 del llamado Lodo Maccanico-Schifani, solicitado por el partido Italia dei Valori, de Antonio di Pietro, conforme al procedimiento establecido en el artículo 75 de la Constitución italiana ${ }^{18}$. La sentencia de la Corte admitió la solicitud de referéndum en los términos solicitados por sus proponentes. Sin embargo, el referéndum derogatorio finalmente no tuvo lugar porque la oficina central para el referéndum reconoció que la norma objeto del referéndum (el artículo 1 de la Ley), no se encontraba ya presente en el ordenamiento jurídico al haber sido declarada inconstitucional. El referéndum, obviamente, había sido solicitado con anterioridad a la parcial derogación de la ley, ante la posibilidad de que la Corte Costituzionale lo hubiese declarado conforme a la Constitución.

15 PUGIOTTO, Andrea. «Sull'immunità delle «alte cariche» una sentenza di «mecí silenzi». Diritto \& Giustizia, número 5, 2004.

16 "La necesidad de la aprobación de una ley constitucional, de hecho, habria sido la inevitable consecuencia de la configuración de la suspensión en forma de una verdadera y propia inmunidad, para cuyo régimen sería una suerte de reserva de ley constitucional». GIUPPONI, Tommaso F. «Questo o quello per me pari (non) sono. Il lodo Maccanico-Schifani di fronte alla Corte costituzionale». Forum Quaderni Costituzionali, 2004.

${ }^{17}$ La Corte Constitucional italiana resuelve sobre la admisibilidad o no de un referéndum derogativo. Artículo 2 de la ley constitucional de 11 de marzo de 1953: «Spetta alla Corte costituzionale giudicare se le richieste di referendum abrogativo presentate a norma dell'art. 75 della Costituzione siano ammissibili ai sensi del secondo comma dell'articolo stesso. Le modalità di tale giudizio saranno stabilite dalla legge che disciplinerà lo svolgimento del referendum popolare».

${ }_{18}$ Artículo 75 de la Constitución italiana: "E indetto referendum popolare per deliberare l'abrogazione, totale o parziale, di una legge o di un atto avente valore di legge, quando lo richiedono cinquecentomila elettori o cinque Consigli regionali. Non è ammesso il referendum per le leggi tributarie e di bilancio, di amnistia e di indulto, di autorizzazione a ratificare trattati internazionali. Hanno diritto di partecipare al referendum tutti i cittadini chiamati ad eleggere la Camera dei deputati. La proposta soggetta a referendum è approvata se ha partecipato alla votazione la maggioranza degli aventi diritto, e se è raggiunta la maggioranza dei voti validamente espressi. La legge determina le modalità di attuazione del referéndum». 


\section{EL LODO ALFANO}

La Ley de 23 de julio de 2008, número 124 —llamada Lodo Alfano por el ministro de Justicia del mismo nombre que la propuso, Angelino Alfano- es una ley que versa sobre las disposiciones en materia de suspensión del proceso penal respecto de los altos cargos del Estado ${ }^{19}$, con la variante, respecto del Lodo Maccanico-Schifani, de no incluir en su elenco al Presidente de la Corte Costituzionale, por sugerencia de la sentencia que declara su parcial inconstitucionalidad $^{20}$.

El proyecto de ley, de artículo único y ocho puntos ${ }^{21}$, se centra, respecto de los altos cargos, en las cuatro magistraturas del Estado antes mencionadas y fue

19 Exactamente, "Disposizioni in materia di sospensione del processo penale nei confronti delle alte cariche dello Stato».

20 La sentencia afirmaba la falta de justificación de incluir, en el elenco de altos cargos sujetos a inmunidad, al Presidente de la Corte Costituzionale, puesto que, a tenor del artículo 3 de la ley constitucional de 9 de febrero de 1948, número 1, "Finché durano in carica, i giudici della Corte costituzionale godono della immunità accordata nel secondo comma dell'art. 68 della Costituzione ai membri delle due Camere. L'autorizzazione ivi prevista è data dalla Corte costituzionale». Es decir, la citada ley constitucional extiende la inmunidad prevista a los miembros de las Cámaras a todos los miembros de la Corte Constitucional, por lo que la previsión hecha al Presidente de la Corte carece jurídicamente de fundamento, al quedar obviamente incluido en el citado precepto.

21 Artículo 1: "1. Salvi i casi previsti dagli articoli 90 e 96 della Costituzione, i processi penali nei confronti dei soggetti che rivestono la qualità di Presidente della Repubblica, di Presidente del Senato della Repubblica, di Presidente della Camera dei deputati e di Presidente del Consiglio dei ministri sono sospesi dalla data di assunzione e fino alla cessazione della carica o della funzione. La sospensione si applica anche ai processi penali per fatti antecedenti l'assunzione della carica o della funzione.

2. L'imputato o il suo difensore munito di procura speciale può rinunciare in ogni momento alla sospensione.

3. La sospensione non impedisce al giudice, ove ne ricorrano i presupposti, di provvedere, ai sensi degli articoli 392 e 467 del codice di procedura penale, per l'assunzione delle prove non rinviabili.

4. Si applicano le disposizioni dell'articolo 159 del codice penale.

5. La sospensione opera per l'intera durata della carica o della funzione e non è reiterabile, salvo il caso di nuova nomina nel corso della stessa legislatura né si applica in caso di successiva investitura in altra delle cariche o delle funzioni.

6. Nel caso di sospensione, non si applica la disposizione dell'articolo 75, comma 3, del codice di procedura penale. Quando la parte civile trasferisce l'azione in sede civile, i termini per comparire, di cui all'articolo 163-bis del codice di procedura civile, sono ridotti alla metà, e il giudice fissa l'ordine di trattazione delle cause dando precedenza al processo relativo all'azione trasferita.

7. Le disposizioni di cui al presente articolo si applicano anche ai processi penali in corso, in ogni fase, stato o grado, alla data di entrata in vigore della presente legge.

8. La presente legge entra in vigore il giorno successivo a quello della sua pubblicazione nella Gazzetta Ufficiale». 
aprobado por el Consejo de Ministros de 26 de junio de 2008, con el objetivo de "tutelar la exigencia absoluta de la continuidad y regularidad del ejercicio de las más altas funciones públicas, la medida respeta el pleno equilibrio de las garantías constitucionales en materia penal, en coherencia con lo que establece la sentencia número 24 de la Corte Constitucional. Para conseguir el desarrollo sereno de las funciones de las que son responsables los más altos cargos del Estado, la suspensión opera también por actos cometidos con anterioridad a la duración del cargo, es renunciable y no reiterable y afecta sólo a los procesos y no a la instrucción, se aplica a los delitos extrafuncionales y no prejuicia los efectos civiles. Además, en caso de suspensión del proceso, la medida prevé que se suspenda el curso de la prescripción de los delitos impugnados y que el juez, en caso de que se recurran los presupuestos, pueda obtener las pruebas urgentes y no reenviables ${ }^{22}$ ».

El mismo Berlusconi, interrogado sobre el Lodo, afirmó que «El Presidente del Consejo, como consecuencia de las persecuciones a las que ha estado sometido desde hace 14 años hasta ahora, habría tenido que ir, un día si y otro no a los tribunales, no pudiendo participar ni en los consejos de ministros ni en el G8. Es entonces cuando se comprueban cosas en Italia, con la magistratura que subvierte los resultados de las elecciones y el voto de los italianos, el lodo del que se habla me parece lo minimo que una democracia puede hacer para defender su propia libertadi.

La nueva ley pretendía hacerse eco de las sugerencias de la Corte Constitucional en su sentencia de inconstitucionalidad del Lodo Maccanico-Schifani para sortear la inconstitucionalidad y se diferencia, en lo que respecta al contenido, en el hecho de establecer un período de tiempo determinado para la suspensión de los procesos penales a las altas magistraturas. Asimismo, establece la posibilidad, a pesar de la suspensión, de continuar con la acción de responsabilidad civil, algo que no sucedía en el Lodo Maccanico-Schifani y excluir, como antes se ha mencionado, del elenco de altos cargos que se encuentran protegidos por la Ley, al Presidente de la Corte Costituzionale. Por último permite, a pesar de la protección que otorga la Ley, que el imputado pueda renunciar a dicha protección que se le otorga, con lo que el eventual proceso seguiría su curso. El «blindaje o escudo procesal» deja de ser obligatorio, para pasar a ser opcional, voluntario, aunque opere de forma automática.

Es importante destacar, - a pesar de que socialmente así haya sido considerado- que el Lodo, la Ley, no establece una «inmunidad procesal» por razón del cargo, sino tan sólo una «suspensión» de los eventuales procesos, un «aplazamiento». La inmunidad supondría una «sustracción al poder judicial. La sus-

\footnotetext{
${ }^{22}$ Comunicado del Consejo de Ministros de 27 de junio de 2008.
} 
pensión del juicio incide, al contrario, sólo sobre los «tiempos» del proceso, con recaída sobre la eficiencia del mismo ${ }^{23}$ ". La suspensión, que opera durante el tiempo que el titular se encuentre en el cargo, no distingue ni la naturaleza ni la gravedad de los delitos. Se aplica a todos los delitos. La suspensión, asimismo, afecta a la prescripción de los delitos, no sigue su curso, retomándolo desde el momento en que cesa la causa que motivó la suspensión.

Desde un punto de vista social y político, el Lodo fue objeto de enconadas críticas doctrinales y fuertes polémicas sociales, al ser considerado — de nuevoun instrumento de salvaguarda judicial del Presidente del Consejo de Ministros, Silvio Berlusconi, sobre todo, por la rapidez con la que fue promulgado ${ }^{24}$, en medio de varios y graves procesos judiciales.

No obstante, resulta obligado resaltar que la doctrina, en general, no se muestra en contra de la existencia de una suerte de "tratos de favor ${ }^{25}$ ", sino de cómo, desde un punto de vista legislativo, con esta Ley, ha sido establecida e implementada la inmunidad en favor de las altas magistraturas del Estado, desequilibrando el orden constitucional ${ }^{26}$. No se cuestiona un régimen particular, habida cuenta de la representatividad y alta consideración política de los sujetos, sino de su particular marco jurídico, una ley ordinaria. Como ya afirmase la sentencia de inconstitucionalidad del Lodo Maccanico-Schifani, «el principio de igualdad comporta de hecho que, si situaciones iguales exigen igual disciplina, situaciones diversas pueden implicar normativas diversas».

${ }^{23}$ CHIOLA, Claudio. «Lamentatio sulla pietra tombale del Lodo Alfano». Forum Quaderni Costituzionali, 2009.

24 Tan sólo 24 días separan la presentación de la Ley en el Parlamento a su entrada en vigor.

25 «Tratos de favor pueden ser oportunos e incluso recomendables, para corregir situaciones de desigualdad o para asegurar el cumplimiento de funciones públicas con una modalidad adecuada, al perseguir un interés general. Se convierten en insoportables y a menudo ilegítimos, cuando no se vislumbra una razón plausible. La línea de demarcación entre lo permitido y lo prohibido recorre el filo del razonable fundamento del privilegio, por la consciencia del carácter históricamente relativo de la afirmación del fundamento». ORLANDI, Renzo. "Illegittimi privilegi». Cassazione penale, número 1, 2010.

26 «El principio de igualdad, sub specie paridad de tratamiento respecto a la jurisdicción, es afirmado desde la primera sentencia como elemento genético del Estado de Derecho, y su contracción debe encontrar justificación en nombre de un valor de igual grado, de modo que el sistema se recomponga en una unidad dejando invariado el diseño de los equilibrios constitucionales. La tutela de la función pública es un interés de rango superior, que puede ser invocado para motivar una flexión del principio de igualdad, pero que no puede en ningún caso llegar a su total sacrificio, porque generaría un desequilibrio tan evidente que alteraría no sólo el equilibrio entre poderes, sino la misma identidad del orden constitucionab. SGRÒ, Francesca. «Dalla sentenza n. 24/2004 alla sentenza n. 262/2009: un'opera in due atti». Forum Quaderni Costituzionali, 2009. 
Sin embargo, con la configuración con la que se presentó, el Gobierno obvió que existía, de hecho, una normativa que protegía - y protege- a las cuatro altas magistraturas del Estado. En efecto, el Presidente del Consejo de Ministros goza de las prerrogativas reconocidas por la ley constitucional número 1, de 16 de enero de $1989^{27}$, que modificó el artículo 96 de la Constitución italiana, que le reconoce que él y sus ministros pueden ser procesados, por actos cometidos en el ejercicio de sus funciones, sólo con autorización de la Cámara a la que pertenezcan. El Presidente de la República, en cambio, no puede ser perseguido penalmente por actos cometidos en el ejercicio de sus funciones, con excepción de delitos contra la Constitución o alta traición ${ }^{28}$. Por último, por lo que respecta a los presidentes de las Cámaras, gozan de la protección en cuanto parlamentarios, tal y como les reconoce la propia Constitución en su artículo $68^{29}$.

En lo que se refiere a la fundamentación jurídica que sostiene la sentencia, los motivos que justifican la declaración de inconstitucionalidad se podrían resumir en dos. En primer lugar, «la introducción de una suerte de derecho particular ${ }^{30}$ ", especial si se quiere, que deroga implícitamente el artículo 3 de la Constitución italiana, que consagra la igualdad, sin una ley constitucional que lo ampare y en segundo lugar, la falta de racionalidad de la norma que limita la prerrogativa a los cuatro altos cargos expresamente mencionados en la ley, creando una disparidad en el trato al instituir una suspensión procesal para los

27 La actual redacción del artículo 96 de la Constitución italiana es la transcripción del artículo 1 de la citada ley constitucional número 1 de 1989, de 16 de febrero. Artículo 96: «Il Presidente del Consiglio dei ministri ed $i$ ministri, anche se cessati dalla carica, sono sottoposti, per i reati commessi nell'esercizio delleloro funzioni, alla giurisdizione ordinaria, previa autorizzazione del Senato della Repubblica o della Camera dei deputati, secondo lenorme stabilite con legge costituzionale».

28 Artículo 90 de la Constitución italiana: «Il Presidente della Repubblica non è responsabile degli atti compiuti nell'esercizio delle sue funzioni, tranne che per alto tradimento o per attentato alla Costituzione. In tali casi è messo in stato di accusa dal Parlamento in seduta comune, a maggioranza assoluta dei suoi membrì.

${ }^{29}$ Este artículo fue modificado por la ley constitucional número 3, de 29 de octubre de 1993. Artículo 68 de la Constitución italiana: "I membri del Parlamento non possono essere chiamati a risponderedelle opinioni espresse e dei voti dati nell'esercizio delle loro funzioni. Senza autorizzazione della Camera alla quale appartiene, nessunmembro del Parlamento può essere sottoposto a perquisizione personale o domiciliare, né può essere arrestato o altrimenti privatodella libertà personale, o mantenuto in detenzione, salvo che in esecuzione di una sentenza irrevocabile di condanna, ovvero se sia colto nell'atto di commettere un delitto per il quale è previsto l'arresto obbligatorio in flagranza. Analoga autorizzazione è richiesta per sottoporre i membri delParlamento ad intercettazione, in qualsiasi forma, di conversazioni o comunicazioni e a sequestro di corrispondenza».

30 MORRONE, Andrea. «La Corte costituzionale sul «lodo Alfano»: una risposta tardiva?». Quaderni Costituzionali, número 4, 2009. 
eventuales procesos de los que fueren parte, vulnerando con ello la tutela judicial efectiva $^{31}$.

La sentencia, en cualquier caso, y a pesar del precedente del Lodo Maccanico-Schifani y su parcial declaración de inconstitucionalidad, deja claro al Parlamento, por segunda vez, cuál es «la vía maestra en materia de inmunidad de los órganos políticos: la ley constitucional ${ }^{32}{ }$, sin que sea posible subvertir jurídicamente el orden constitucional con una modificación de la Constitución por vía de una simple ley ordinaria. Desde un punto doctrinal, la sentencia ha sido muy celebrada, al considerar que se ha garantizado la igualdad de todos los ciudadanos y la tutela de una jurisdicción universal, con el ejercicio obligatorio de la acción penal, tal y como consagra el artículo 112 de la Constitución ${ }^{33}$.

\section{DERECHO COMPARADO}

Una somera visión a los ordenamientos jurídicos del resto de los países europeos nos permite atisbar, sin exhaustiva profundidad, que la configuración jurídica del Lodo constituye una anomalía, una asimetría jurídica que no existe en ningún país de la Unión Europea.

En efecto, sólo la Constitución griega, en su artículo $49^{34}$, y la Constitución portuguesa, en su artículo $130^{35}$, contemplan un régimen de suspensión del pro-

${ }^{31}$ La sentencia es taxativa al afirmar que «se debe concluir que la suspensión procesal prevista por la norma censurada va dirigida esencialmente a la protección de las funciones propias de los componentes y de los titulares de algunos órganos constitucionales y, contemporáneamente, crea una evidente disparidad de tratamiento frente a la jurisdicción. Subsisten, por tanto, los requisitos propios de las prerrogativas constitucionales, con la consecuente inidoneidad de la ley ordinaria a disciplinar la materia. En particular, la normativa censurada atribuye a los titulares de cuatro altos cargos institucionales un excepcional e innovador estatus protector, que no es deducible de las normas constitucionales. Ella, por lo tanto, no constituye fuente de rango idóneo a disponer la materia».

32 GIUPPONI, Tommaso F. «La sentenza sul «lodo Alfano»: le possibili prospettive di riforma». Quaderni Costituzionali, número 4, 2009.

33 Artículo 112 de la Constitución: «Il pubblico ministero ha l'obbligo di esercitare l'azione penale».

34 Artículo 49.1 de la Constitución de Grecia de 1975: «El Presidente de la República no será responsable en absoluto por actos realizados en el ejercicio de sus funciones, salvo en caso de alta traición o de violación deliberada de la Constitución. En cuanto a los actos que no tengan relación con el ejercicio de sus funciones, se suspenderá toda actuación penal hasta la expiración del mandato presidenciali.

35 Artículo 130 de la Constitución portuguesa de 1976: «1. Por crimes praticados no exercício das suas funçôes, o Presidente da República responde perante o Supremo Tribunal de Justiça. 2. A iniciativa do processo cabe à Assembleia da República, mediante proposta de um quinto e deliberação aprovada por maioria de dois terços dos Deputados em efectividade de funçóes. 3. A condenação implica a 
cedimiento penal hasta el fin del mandato por actos penalmente relevantes, pero circunscrito exclusivamente al Jefe del Estado.

En Francia, tras la reforma constitucional producida con la ley constitucional 238-2007, que ha modificado el Título IX de la Constitución, se han modificado los artículos $67^{36}$ y $68^{37}$, con lo que el Presidente de la República no responde por actos cometidos en el ejercicio de sus funciones, con la excepción prevista en los artículos 53-2 y 68 y no puede ser procesado mientras dure su mandato. Por lo que respecta a la responsabilidad penal de los miembros del Gobierno, se encuentra en los artículos 68-138 y 68-2 $2^{39}$ de la Constitución, que establecen que los

destituição do cargo e a impossibilidade de reeleição. 4. Por crimes estranhos ao exercício das suas funções o Presidente da República responde depois de findo o mandato perante os tribunais comuns».

36 Artículo 67 de la Constitución francesa de 1958: «Le Président de la République n'est pas responsable des actes accomplis en cette qualité, sous réserve des dispositions des articles 53-2 et 68. Il ne peut, durant son mandat et devant aucune juridiction ou autorité administrative française, être requis de témoigner non plus que faire l'objet d'une action, d'un acte d'information, d'instruction ou de poursuite. Tout délai de prescription ou de forclusion est suspendu. Les instances et procédures auxquelles il est ainsi fait obstacle peuvent être reprises ou engagées contre lui à l'expiration d'un délai d'un mois suivant la cessation des fonctions.

37 Artículo 68 de la Constitución francesa de 1958: «Le Président de la République ne peut être destitué qu'en cas de manquement à ses devoirs manifestement incompatible avec l'exercice de son mandat. La destitution est prononcée par le Parlement constitué en Haute Cour. La proposition de réunion de la Haute Cour adoptée par une des assemblées du Parlement est aussitôt transmise à l'autre qui se prononce dans les quinze jours. La Haute Cour est présidée par le président de l'Assemblée nationale. Elle statue dans un délai d'un mois, à bulletins secrets, sur la destitution. Sa décision est d'effet immédiat. Les décisions prises en application du présent article le sont à la majorité des deux tiers des membres composant l'assemblée concernée ou la Haute Cour. Toute délégation de vote est interdite. Seuls sont recensés les votes favorables à la proposition de réunion de la Haute Cour ou à la destitution. Une loi organique fixe les conditions d'application du présent articlei.

38 Artículo 68-1 de la Constitución francesa de 1958: "Les membres du gouvernement sont pénalement responsables des actes accomplis dans l'exercice de leurs fonctions et qualifiés crimes ou délits au moment où ils ont été commis. Ils sont jugés par la Cour de justice de la République. La Cour de justice de la République est liée par la définition des crimes et délits ainsi que par la détermination des peines telles qu'elles résultent de la loì.

39 Artículo 68-2 de la Constitución francesa de 1958: «La Cour de justice de la République comprend quinze juges : douze parlementaires élus, en leur sein et en nombre égal, par l'Assemblée Nationale et par le Sénat après chaque renouvellement général ou partiel de ces assemblées et trois magistrats du siège à la Cour de cassation, dont l'un préside la Cour de justice de la République. Toute personne qui se prétend lésée par un crime ou un délit commis par un membre du gouvernement dans l'exercice de ses fonctions peut porter plainte auprès d'une commission des requêtes. Cette commission ordonne soit le classement de la procédure, soit sa transmission au procureur général près la Cour de cassation aux fins de saisine de la Cour de justice de la République. Le procureur général près la Cour de cassation peut aussi saisir d'office la Cour de justice de la République sur avis conforme de la commission des requêtes. Une loi organique détermine les conditions d'application du présent article».

(C) UNED. Revista de Derecho Politico

N. ${ }^{\circ} 78$, mayo-diciembre 2010, págs. 317-334 
miembros del Gobierno son penalmente responsables de los actos cometidos en el ejercicio de sus funciones. Por los delitos cometidos con anterioridad a la toma de posesión de cargo o que no estuviesen relacionados con el ejercicio de la función, los miembros del Gobierno se encuentran sometidos, como cualquier otro ciudadano, al régimen ordinario de la responsabilidad penal.

Por lo que respecta a Alemania, el artículo 46 de la Ley Fundamental de Bonn ${ }^{40}$ regula la inmunidad de los miembros del Bundestag, circunscrita fundamentalmente a su labor parlamentaria y a sus declaraciones, y establece que sólo podrán ser procesados con expresa autorización del Bundestag. Por lo que respecta al Jefe del Estado, al Bundespräsident, su estatus se encuentra en el artículo $61^{41}$ de la Ley Fundamental de Bonn, y se le aplica el artículo 60.4, que dispone la aplicación analógica del artículo 46, apartados 2, 3 y 4, concluyendo que, como los miembros del Parlamento, el Presidente de la República no puede ser arrestado, ni objeto de acción alguna que pudiese vulnerar su libertad personal, salvo la excepción recogida en el artículo $18^{42}$ de la Ley Fundamental, excepción, no obstante, que reconoce a todos los ciudadanos que desean atentar

40 Artículo 46 de la Ley Fundamental de Bonn de 1949: «1. Los diputados no podrán en ningún momento ser sometidos a un procedimiento judicial o disciplinario ni responsabilizados de otra forma fuera del Bundestag a causa de su voto o de una declaración que hicieran en el Bundestag o en una de sus comisiones. Esto no rige para las ofensas calumniosas. 2. A causa de actos sujetos a sanción penal, un diputado puede ser responsabilizado o detenido sólo con la autorización del Bundestag, a no ser que sea detenuido en delito flagrante o durante el día siguiente de haber cometido el acto. 3. La autorización del Bundestag es necesaria igualmente para toda otra restricción de la libertad personal de un diputado o para iniciarcontra un diputado el procedimiento previsto en el artículo 18. 4. Todo proceso penal y todo procedimiento según el artículo 18 iniciado contra un diputado, toda detención y toda otra limitación de la libertad personal, deberán ser suspendidos a solicitud del Bundestag».

41 Artículo 61 de la Ley Fundamental de Bonn de 1949: «1. El Bundestag o el Bundesrat podrán acusar al Presidente Federal ante la Corte Constitucional Federal por violación dolosa de la Ley Fundamental o de otra ley federal.. La solicitud de formulación de la acusación deberá ser presentada, al menos, por una cuarta parte de los miembros del Bundestag o por una cuarta parte de los votos del Bundesrat. La resolución para formular la acusación requiere la mayoría de dos tercios de los miembros del Bundestag o de dos tercios de los votos del Bundesrat. La acusación estará representada por un delegado del órgano acusador. 2. Si la Corte Constitucional Federal comprueba que el Presidente Federal es culpable de una violación dolosa de la Ley Fundamental o de otra ley federal, podrá separarlo del cargo. Mediante una disposición cautelar podrá resolver, después de presentada la acusación, el impedimento del Presidente Federal para el ejercicio de su cargo».

42 Artículo 18 de la Ley Fundamental de Bonn de 1949: "Quien, para combatir el régimen fundamental de libertad y democracia, abuse de la libertad de expresión de opinión, particularmente de la libertad de prensa, (artículo 5, apartado 1), de la libertad de enseñanza (artículo 5, apartado 3), de reunión (artículo 8), de asociación (artículo 9), del secreto de las comunicaciones postales y de las telecomunicaciones (artículo 10), asi como del derecho de propiedad (artículo 14) y del de asilo (artículo 16a) pierde estos derechos fundamentales. Lan privación y su alcance serán declarados por la Corte Constitucional Federab. 
contra «el régimen fundamental de libertad y democracia», tal y como se expone en el mismo artículo. Resulta, sin embargo, importante destacar que en Alemania el canciller y sus ministros son considerados «funcionarios», — aunque sean funcionarios de alto nivel — por lo que se les aplica el régimen general de los funcionarios. Carecen de inmunidad fuera del ejercicio de sus funciones de Gobierno, siendo responsables como cualquier otro ciudadano, sin gozar de un estatus especial por acciones ajenas a sus responsabilidades gubernamentales.

Por último, aunque pueda parecer superfluo, resulta obligado destacar cuál es el régimen que se encuentra previsto para los sujetos afectados por el Lodo Alfano en nuestro ordenamiento jurídico.

Por lo que respecta a la Jefatura del Estado, el artículo $56.3^{43}$ de la Constitución consagra su inviolabilidad e irresponsabilidad del Rey, al ser sometidos sus actos a refrendo, por lo que la responsabilidad última es del Gobierno, que es quien refrenda las acciones del Rey.

El Presidente del Gobierno y sus ministros, tal y como así lo establece el artículo $102^{44}$ de la Constitución implícitamente, poseen la misma inmunidad que cualquier senador o diputado. Su privilegio procesal es el aforamiento, consistente en que sólo pueden ser procesados si así lo autoriza el Congreso de los Diputados por mayoría absoluta, tal y como establece el artículo 169 del Reglamento del Congreso ${ }^{45}$, y su proceso se sustanciaría ante la Sala de lo Penal del Tribunal Supremo, que es quien juzga a los aforados.

43 Artículo 56.3 de la Constitución: "La persona del Rey es inviolable y no está sujeta a responsabilidad. Sus actos estarán siempre refrendados en la forma establecida en el artículo 64, careciendo de validez sin dicho refrendo, salvo lo dispuesto en el artículo 65.2».

44 Artículo 102 de la Constitución: «1. La responsabilidad criminal del Presidente y los demás miembros del Gobierno será exigible, en su caso, ante la Sala de lo Penal del Tribunal Supremo. 2. Si la acusación fuere por traición o por cualquier delito contra la seguridad del Estado en el ejercicio de sus funciones, sólo podrá ser planteada por iniciativa de la cuarta parte de los miembros del Congreso, y con la aprobación de la mayoría absoluta del mismo. 3. La prerrogativa real de gracia no será aplicable a ninguno de los supuestos del presente artículo».

45 Artículo 169 del Reglamento del Congreso de los Diputados: «1. Formulada por escrito y firmada por un número de Diputados no inferior a la cuarta parte de los miembros del Congreso la iniciativa a que se refiere el artículo 102.2 de la Constitución, el Presidente convocará una sesión secreta del Pleno de la Cámara para su debate y votación. 2. El debate se ajustará a las normas previstas para los de totalidad. El afectado por la iniciativa de acusación podrá hacer uso de la palabra en cualquier momento del debate. La votación se hará por el procedimiento previsto en el número 2.o del apartado 1 del artículo 87 de este Reglamento y se anunciará con antelación por la Presidencia la hora en que se llevará a cabo. 3. Si la iniciativa de acusación fuera aprobada por la mayoría absoluta de los miembros de la Cámara, el Presidente del Congreso lo comunicará al del Tribunal Supremo, a efectos de lo dispuesto en el artículo 102.1 de la Constitución. En caso contrario se entenderá rechazada la iniciativa».

(C) UNED. Revista de Derecho Político

N. ${ }^{\circ} 78$, mayo-diciembre 2010, págs. 317-334 
Los Presidentes del Congreso y del Senado gozan del mismo régimen jurídico que el resto de los parlamentarios, recogido en el artículo $71^{46}$ de la Constitución, salvo que pueden ejercer, en el ámbito de su respectiva Cámara, todas las funciones administrativas y las funciones de policía, tal y como recoge el artículo $72.3^{47}$ de la Constitución.

\section{CONCLUSIÓN}

La sentencia 262/2009, de 7 de octubre, de la Corte Costituzionale, que declara inconstitucional el Lodo Alfano, constata, desde un punto de vista de derecho comprado, una extraña asimetría jurídica. Un análisis pormenorizado de los ordenamientos jurídico-constitucionales de varios de los países de la Unión Europea, permite inferir que tan sólo dos países de nuestro entorno han configurado una suerte de suspensión procesal para las altas magistraturas del Estado, pero que se circunscribe exclusivamente al Jefe de Estado. Estos países son Grecia y Portugal.

En ningún país de la Unión Europea —ni Alemania, ni Francia, ni desde luego España- el jefe del Ejecutivo posee un escudo procesal que "congele», aunque sea temporalmente, su responsabilidad penal. Cierto es que no se puede, en puridad, hablar de inmunidad procesal, sino de suspensión del proceso mientras el sujeto ostente el cargo objeto de la suspensión. En la práctica, sin embargo, la suspensión constata un «derecho particular», algo no sólo inconstitucional, sino manifiestamente antidemocrático que conculca los derechos fundamentales y las libertades públicas propias de un Estado de Derecho.

En efecto, la existencia de un derecho particular choca, de manera frontal, con el principio de igualdad con carácter genérico, y con la igualdad ante la ley en particular. Si bien es cierto que la aplicación del principio de igualdad a determinados sujetos, como sostiene la sentencia de declaración de inconstitucionalidad del Lodo Maccanico-Schifani, "comporta de hecho que, si situaciones igua-

46 Artículo 71 de la Constitución: «1. Los Diputados y Senadores gozarán de inviolabilidad por las opiniones manifestadas en el ejercicio de sus funciones. 2. Durante el periodo de su mandato los Diputados y Senadores gozarán asimismo de inmunidad y sólo podrán ser detenidos en caso de flagrante delito. No podrán ser inculpados ni procesados sin la previa autorización de la Cámara respectiva. 3. En las causas contra Diputados y Senadores será competente la Sala de lo Penal del Tribunal Supremo. 4. Los Diputados y Senadores percibirán una asignación que será fijada por las respectivas Cámaras.

${ }^{47}$ Artículo 71.3 de la Constitución: «Los Presidentes de las Cámaras ejercen en nombre de las mismas todos los poderes administrativos y facultades de policía en el interior de sus respectivas sedesn. 
les exigen igual disciplina, situaciones diversas pueden implicar normativas diversas", no menos cierto es que la suspensión, tal y como está planteada, confiere una inmunidad a su titular, no sólo por operar automáticamente, aunque pueda ser rechazada por su titular, sino porque, a diferencia de lo que sucede en nuestro ordenamiento con los aforados, — a los que su condición no les otorga inmunidad por razón de su cargo, sino que el proceso penal se sustancia ante un órgano especial, la Sala de lo Penal del Tribunal Supremo, previa autorización por mayoría absoluta del Congreso o del Senado- la suspensión comporta un stand by del proceso, una parálisis del mismo que bloquea el obligatorio y constitucional ejercicio de la acción penal.

Se podrían justificar, — por el carácter representativo que poseen determinadas magistraturas - ciertos «privilegios», pero nunca un derecho particular que vulnerase, de manera flagrante, una columna vertebral de cualquier ordenamiento democrático: el principio de igualdad.

Pero además, el hecho de instituir, vía ley ordinaria, una modificación de la Constitución, algo que implicaría una legge costituzionale, hace de esta ley, por segunda vez - el precedente fue el citado Lodo Maccanico-Schifaniuna tautología. Han sido dos las veces que la Corte Costituzionale italiana ha marcado la línea roja del establecimiento de una suerte de inmunidad para las altas magistraturas del Estado: la ley constitucional, no una simple ley ordinaria.

El análisis expuesto revela que esta ley es innecesaria — toda vez que, como ya se ha expuesto, las cuatro magistraturas se encuentran jurídicamente protegidas-, políticamente cuestionable y, como ya ha afirmado prolijamente la sentencia de la Corte, manifiestamente inconstitucional.

\section{BIBLIOGRAFÍA}

CHIOLA, Claudio. Lamentatio sulla pietra tombale del lodo alfano. Forum Quaderni Costituzionali, 2009.

GIUPPONI, Tommaso. Questo o quello per me pari (non) sono. Il lodo maccanicoschifani di fronte alla corte costituzionale. Forum quaderni costituzionali, 2004.

GIUPPONI, Tommaso. La sentenza sul «lodo alfano»: le possibili prospettive di riforma. Quaderni Costituzionali, número 4, 2009.

MORRONE, Andrea. La corte costituzionale sul «Lodo Alfano»: una risposta tardiva? Quaderni Costituzionali, número 4, 2009.

ORLANDI, Renzo. Illegittimi privilegi. Cassazione Penale, número 1, 2010.

SGRÒ, Francesca. Dalla sentenza n. 24/2004 alla sentenza 262/2009: un'opera in due atti. Forum Quaderni Costituzionali, 2009. 
PUGIOTTO, Andrea. Sull'immunità delle «alte cariche» una sentenza di «mezzi silenzi». Diritto \& Giustizia, número 7, 2004.

VITALE, Agostino. Breve commentario della nuova costituzione italiana. Edizioni Philos, Roma, 2003. 